\title{
Volleyball injuries: a survey of injuries of Scottish National League male players
}

\author{
James Watkins PhD and Brian N. Green MSc \\ Division of Physical Education, Sport and Outdoor Education, Jordanhill College, Glasgow
}

\begin{abstract}
Injuries sustained in male volleyball players in the first division of the Scottish National League during the 1989-1990 season were investigated by means of a questionnaire survey. Forty-six injuries were reported, representing an incidence of 0.53 injuries per player. Damage to muscles, tendons and ligaments accounted for most of the injuries. The cause of most injuries was blocking or spiking. In $74 \%$ of cases the injured players were able to resume training and playing within 2 weeks of the injury. In $10 \%$ of cases the injured players were unable to train or play for 7-14 weeks.
\end{abstract}

Keywords: Injuries, volleyball, males

In terms of the number of participants, volleyball is one of the most popular games in the world. The International Volleyball Federation represents about 150 million players in approximately 170 countries $^{1}$.

Volleyball is a dynamic sport involving rapid and forceful movements of the body as a whole, both horizontally and vertically, and of the arm and hand when spiking the ball. Because of the large forces involved in such movements, it is inevitable that injuries occur. Whereas the incidences of injuries which occur in some sports, such as tennis, gymnastics and swimming, have been well documented over a fairly long period ${ }^{2}$, there are few studies of the incidence of injuries in volleyball ${ }^{3}$. Furthermore, most of this work seems to have been carried out over the past 6 years $^{3-6}$. Comparison of the results of these studies is difficult because of differences in research design and the variables investigated. However, most studies show a fairly high incidence of injuries to fingers, ankles and knees. In general, most injuries appear to result from blocking and spiking actions during matches, but a relatively large proportion of injuries appears to occur during training.

A number of injury risk factors have been identified, eg techniques (movement patterns) of jumping, landing and hitting, hardness of the playing surface, shock absorbency of shoes, level of physical conditioning 7 . However, the relative importance of these and other risk factors, such as wearing

Address for correspondence: Dr James Watkins, Division of PE, Sports and Outdoor Education, Jordanhill College, Glasgow G13 1PP, UK

(C) 1992 Butterworth-Heinemann Ltd 0306-3674/92/020135-03 protective clothing, has not yet been established. Furthermore, there would appear to be little information on the incidence and severity of the different types of injuries which occur in volleyball.

To date, there are no reported studies of volleyball injuries in the UK. The objectives of the present investigation were to determine the incidence and severity of injuries incurred by male volleyball players in the Scottish National League, and to investigate the relative importance of injury risk factors.

\section{Methods}

The method of enquiry for the research was a questionnaire, which was made up of six sections: personal details; volleyball experience; home court (location and playing surface); shoes and socks; use of orthoses and supportive equipment; injuries. The sample population for the survey comprised all players who played in the first division of the men's Scottish National League in the 1989-1990 season. A total of 125 questionnaires was distributed and 86 completed questionnaires were returned. The results are based on an analysis of these 86. In the section on injuries each player was asked to give details of all injuries sustained while training or playing during the season. For the purpose of the survey, an injury was defined as that degree of damage which prevented the player, due to pain or other symptoms, from training or playing for three or more consecutive days immediately after sustaining the injury.

\section{Results and discussion}

The mean (s.d.) age, height and weight of the 86 players were as follows: age 27.7 (4.9) years; height $184(7) \mathrm{cm}$; weight $80.7(7.2) \mathrm{kg}$. Eighty players were right handed and six were left handed. Of the 86 players 13 were current national squad members and another 16 had previously been members of the national squad, 39 other players had received some form of representative honour at a level other than national squad. The sample therefore consisted of an experienced group of players.

\section{Incidence, location, type and severity of injuries}

A total of 46 injuries was sustained by the 86 players, representing an incidence of 0.53 injuries per player. The location of injuries in terms of body parts is 
Table 1. Location of injuries by body part

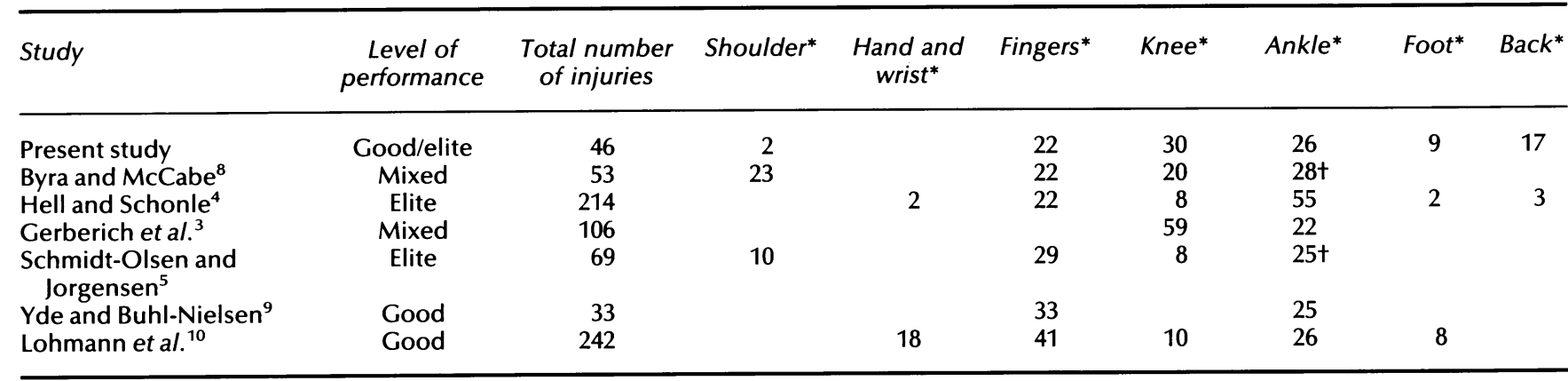

*Values are percentages

tThese figures include both ankle and foot

shown in Table 1 together with comparative data from other studies. The knee, ankle, fingers and back were involved in 30, 26, 22 and $17 \%$ of injuries respectively. The percentage of knee injuries reported here is larger than in the other studies apart from the study by Gerberich et al. ${ }^{3}$. However, the Gerberich study involved the largest mix of players, from recreational to elite and as such is more difficult to compare than the other studies. The percentage of ankle injuries is similar to the figures reported in other studies apart from the study by Hell and Schonle ${ }^{4}$ which involved a questionnaire survey of the injuries to 224 players in the German Federal League over a single season, and the number of injuries (defined in a similar way to that used in the present study) is high (214). In particular, the percentage of ankle injuries is double that found in the other studies. It is not possible, without additional information, to speculate on the reason for such a difference.

In the present study most of the injuries (39 of 46) were diagnosed by professionally trained personnel (medical doctors or physiotherapists) see Table 2. The proportions of the different types of injuries are similar to those reported in other studies ${ }^{4,5,8}$.

The severity of injury was assessed in terms of the number of training sessions and/or matches missed due to the injury. In $74 \%$ of cases, the players concerned recovered sufficiently to resume training or playing within 2 weeks of the injury. However, in $10 \%$ of cases the players were unable to train or play for 7-14 weeks.

Table 2. Diagnosis of injuries

\begin{tabular}{lrr}
\hline & No. & $\%$ \\
\hline Bone fracture & 1 & 2 \\
Dislocation & 1 & 2 \\
Cartilage damage & 3 & 6 \\
Ligament damage & 18 & 39 \\
Tendon damage & 7 & 15 \\
Muscle damage & 9 & 19 \\
\hline
\end{tabular}

\section{Causes of injuries}

Table 3 shows the causes of injuries in terms of some of the main skills (blocking, spiking, field defence, setting) and other elements of the game.

It is clear that the actions of blocking and spiking are major causes of injury, consequently it is not surprising that landing and jumping are also major risk factors. When blocking, a player is vulnerable to injury at three particular parts of the movement: take-off; contact with the ball; landing. The knees, ankles and back are vulnerable at take-off and landing due to the relatively large forces involved and the fingers, hands and wrists are vulnerable due to the high force involved in the impact with the ball. The blocker is particularly vulnerable when landing due to the likelihood of landing on the foot of one of his own team or that of an opposing player. In the present study collision with an opponent or fellow team member was the cause of $13 \%$ and $11 \%$ of injuries, respectively. In the study by Hell and Schonle ${ }^{4}$ the main cause of ankle injuries (55\% of all injuries) was collision with an opponent on landing close to the net. In the same study, the main cause of finger injuries (22\% of all injuries) was that of contact with the ball when blocking. In the present study this factor was the cause of $32 \%$ of finger injuries.

In this study there was a clear positive relationship between playing surface and incidence of injury - the harder the playing surface the higher the incidence of injury. The incidence of injury on composition

Table 3. Causes of injuries

\begin{tabular}{lrr}
\hline & No. & $\%$ \\
\hline Blocking & 19 & 41 \\
Spiking & 14 & 30 \\
Field defence & 5 & 11 \\
Setting & 1 & 2 \\
Landing & 7 & 15 \\
Collision with opponent & 6 & 13 \\
Collision with own team & 5 & 11 \\
General warm up & 3 & 6 \\
\hline
\end{tabular}


flooring, eg Granwood (Granwood Flooring, Derby, UK), was found to be almost three times that on timber surfaces. This finding is similar to that of a study of Italian volleyball players ${ }^{6}$. The use of shock-absorbing insoles in shoes has been shown to reduce the risk of injury when playing on hard surfaces ${ }^{7}$. In this respect it was surprising to find that only nine players $(10 \%)$ in the present survey used shock-absorbing insoles.

\section{Use of supportive equipment}

In the present survey $14-28 \%$ of players used supports for ankles, knees and fingers. Most of the players $(73-89 \%)$ used the supports to prevent re-injury following an earlier injury, and few of the total group of 86 players used strapping $(7 \%)$, knee supports $(3 \%)$ and ankle supports $(3 \%)$ for the purpose of preventing an initial injury. This was surprising in view of the fairly high incidence of injuries to fingers, knees and ankles in this and similar studies ${ }^{4,5,8,10}$.

\section{Treatment of injuries}

It is widely accepted that for most muscle and joint injuries the best form of immediate treatment is ice, compression and elevation (ICE) ${ }^{11}$. In the present study, one or more of the elements of ICE were used in $15 \%$ of cases. Since all of the injuries resulted in pain and/or other symptoms which prevented the players from training or playing for 3 or more consecutive days, the use of ICE in only $15 \%$ is surprising, as most of the injuries were probably serious enough to warrant immediate ICE treatment. It was also surprising to find that in $28 \%$ of cases the players resumed training or playing within a few minutes of injury. In $78 \%$ of cases, players sought further treatment (medical or paramedical) some hours or days after the injury. It is reasonable to assume that this figure could have been much lower had all of the players concerned received immediate ICE treatment followed by rest. Ferretti et al. ${ }^{1}$ suggests that negligence of players, in terms of continuing to train or play following an injury, significantly increases the severity of most injuries.
In conclusion the results of this study indicate that the incidence of injury in the season 1989-1990 was in the region of 0.53 injuries per player. Owing to lack of comparable data it is not possible to say whether this figure is high or low - there are few published studies of volleyball injuries and the studies which are available are difficult to compare due to differences in research design and lack of clarity with regard to important variables.

The implications of the results are that players and coaches should be made more aware of: the importance of ice, compression and elevation in the immediate treatment of injuries; the dangers of aggravating injuries by further activity; and the importance of protective equipment in helping to prevent injury or re-injury.

\section{Acknowledgements}

The assistance of the Scottish Sports Council in funding this research is gratefully acknowledged.

\section{References}

1 Ferretti A, Papandrea P, Conteduca F. Knee injuries in volleyball. Sports Med 1990; 10: 132-8.

2 Richardson AB. Overuse syndromes in baseball, tennis, gymnastics and swimming. Clin Sports Med 1983; 2: 379-90.

3 Gerberich SG, Luhmann .S, Finke C et al. Analysis of severe injuries associated with volleyball activities. Phys Sportsmed 1987; 15: 75-9.

4 Hell H, Schonle C. Ursachen und Prophylaxe typicher Volleyballverletzungen (Causes and prevention of typical volleyball injuries). Zeitschr Orth Grenz 1985; 123: 72-5.

5 Schmidt-Olsen S, Jorgensen U. Pattern of injuries in Danish elite volleyball. Ugeskr Laeger 1987; 149: 473-4.

6 Ferretti A, Puddu G, Mariani PP, Neri M. Jumper's knee: an epidemiological study of volleyball players. Phys Sportsmed 1984; 12: 97-106.

7 Rooser B, Ekbladh R, Lidgren L. The shock absorbing effect of soles and insoles. Int Orth 1988; 12: 335-8.

8 Byra M, McCabe J. Incidence of volleyball injuries. Volleyball Techn J 1981; 7: 55-7.

9 Yde J, Buhl-Nielsen A. Epidemiological and traumatological analysis of injuries in a Danish volleyball club. Ugeskr Laeger 1988; 150: 1022-3.

10 Lohmann M, Holmich P, Overbaek-Pedersen A. Danish EHLASS project. Copenhagen, Denmark: Herlev Hospital, 1988.

11 Peterson L, Renstrom P. Sports Injuries: Their Treatment and Prevention. London: Martin Dunitz, 1986. 